\title{
Transmission of UHF radiowaves through buildings in urban microcell environments
}

Citation for published version (APA):

Jong, de, Y. L. C., Herben, M. H. A. J., Wagen, J-F., \& Mawira, A. (1999). Transmission of UHF radiowaves through buildings in urban microcell environments. Electronics Letters, 35(9), 743-745.

https://doi.org/10.1049/el:19990467

DOI:

10.1049/el:19990467

Document status and date:

Published: 01/01/1999

Document Version:

Publisher's PDF, also known as Version of Record (includes final page, issue and volume numbers)

Please check the document version of this publication:

- A submitted manuscript is the version of the article upon submission and before peer-review. There can be important differences between the submitted version and the official published version of record. People interested in the research are advised to contact the author for the final version of the publication, or visit the $\mathrm{DOI}$ to the publisher's website.

- The final author version and the galley proof are versions of the publication after peer review.

- The final published version features the final layout of the paper including the volume, issue and page numbers.

Link to publication

\section{General rights}

Copyright and moral rights for the publications made accessible in the public portal are retained by the authors and/or other copyright owners and it is a condition of accessing publications that users recognise and abide by the legal requirements associated with these rights.

- Users may download and print one copy of any publication from the public portal for the purpose of private study or research.

- You may not further distribute the material or use it for any profit-making activity or commercial gain

- You may freely distribute the URL identifying the publication in the public portal.

If the publication is distributed under the terms of Article 25fa of the Dutch Copyright Act, indicated by the "Taverne" license above, please follow below link for the End User Agreement:

www.tue.nl/taverne

Take down policy

If you believe that this document breaches copyright please contact us at:

openaccess@tue.nl

providing details and we will investigate your claim. 
Table 2: Performance comparison of glint identification using noise samples

\begin{tabular}{|c|c|c|}
\hline & A & B \\
\hline$c_{1}$ & 0.9387 & 0.9505 \\
\hline$\sigma_{1}$ & 3.2482 & 3.3436 \\
\hline$\sigma_{2}$ & 22.6284 & 24.7782 \\
\hline
\end{tabular}

(A): glint identification using measurements; (B): synthetic glint noise shown in Fig. 2

Results and discussion: In this Section, we present some simulation results to demonstrate the performance of the proposed algorithm. The simulation environment is summarised as follows. The position measurement $y_{k}$ was generated according to eqn. 3 with $x_{k+1}=$ $x_{k}+v_{k} T+a_{k} T / 2$. The initial target position was $x_{0}=10000 \mathrm{~m}$ and the initial velocity was $v_{0}=150 \mathrm{~m} / \mathrm{s}$. The sampling period $T$ was $0.1 \mathrm{~s}$ and the sample size $L$ was 300 . The target manoeuvre was set to occur from $k=151$ to $k=200$ with $a_{k}=40 \mathrm{~m} / \mathrm{s}^{2}$. The size of the trimmed mean filter was $25(N=12)$ and the $M$ in eqn. 7 was 1 . Two sets of measurement noise $v_{k}$ were generated: the first was from a true mixture of two Gaussian distributions and the other was from the synthetic glint model in [1].

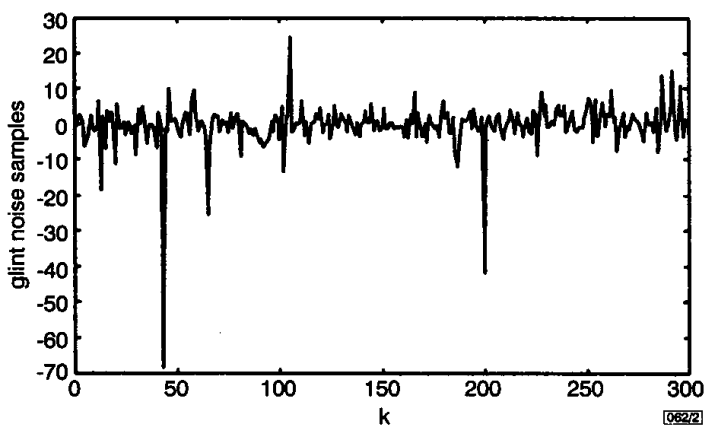

Fig. 2 Synthetic glint noise record

We first examined the results when the measurement noise was generated from a Gaussian mixture of parameters $c_{1}=0.9, \sigma_{1}=1$ and $\sigma_{2}=5$. A Monte Carlo simulation of 50 runs was conducted, and the initial parameter estimates were set as $\hat{c}_{1}=0.75, \hat{\sigma}_{1}=2$ and $\hat{\sigma}_{2}=10$. The mean values and the mean squared errors (MSEs) of the identified parameter are listed in Table 1. As we can see, the mean estimates for the proposed algorithm are very close to the true parameter values. Compared with the identification using the pure noise data, our method yields somewhat larger MSEs.

Next we examine the results for identifying the synthetic glint noise record in Fig. 2. The same initial estimates were used and the results are listed in Table 2. From this Table, we see that the identified parameters using the measurements are similar to those using the pure glint data. Thus, we can conclude that the proposed algorithm is effective for online glint identification.

(C) IEE 1999

Electronics Letters Online No: 19990459

18 March 1999 DOI: 10.1049/el:19990459

Wen-Rong Wu (Department of Communication Engineering, National Chiao-Tung University, Hsinchu, Taiwan, Republic of China)

Kuo-Guan Wu (Department of Computer Science and Information Engineering, National Chiao-Tung University, Hsinchu, Taiwan Republic of China)

\section{References}

1 SANDHU, G.S., and SAYLOR, A.V.: 'A real-time statistical radar target model', IEEE Trans., 1985, AES-21, pp. 490-507

2 wU, W.R.: 'Target tracking with glint noise', IEEE Trans., 1993, AES-29, pp. 174-185

3 DAEIPOUR, E, and BAR-SHALOM, Y.: 'An interacting multiple model approach for target tracking with glint noise', IEEE Trans., 1995 , AES-31, pp. 706-715
4 HEWER, G.A., MARTIN, R.D., and ZEH, J.: 'Robust preprocessing for Kalman filtering of glint noise', IEEE Trans., 1987, AES-23, pp. $120-128$

5 wU, w.R.: 'Maximum likelihood identification of glint noise', IEEE Trans., 1996, AES-32, pp. 41-51

6 HAMPEL, R.R., RONCHETTI, E.M., ROUSSEEUW, P.J., and STAHEL, W.A.: 'Robust statistics' (John Wiley and Sons, 1986)

\section{Transmission of UHF radiowaves through buildings in urban microcell environments}

Y.L.C. de Jong, M.H.A.J. Herben, J.-F. Wagen and A. Mawira

Results are presented of high-resolution time delay and angle-ofarrival measurements behind a large building in an urban microcell. It is demonstrated that in this particular case the electromagnetic field is dominated by contributions resulting from transmission through the building. The associated loss over freespace loss is $<30 \mathrm{~dB}$. This makes clear the importance of modelling propagation through buildings surrounding the base station in the planning stage of urban microcells.

Introduction: The current growth of the personal wireless communications market is pushing operators of mobile radio networks to explore capacity-increasing techniques such as the use of microcells. Whereas the base station (BS) antennas used in conventional macrocells are usually situated at high elevations, the idea of microcells is to place the BS antenna below the average height of the surrounding buildings to confine the radiated power within a small coverage area, such that the same frequency channels can be re-used at short distances without introducing an unacceptable degree of inter-user interference.

The efficient planning of microcells requires an accurate prediction of the electromagnetic field strength distribution. Various groups have been active in the development of so-called deterministic propagation models based on an accurate description of the buildings around the $\mathrm{BS}$, and ray-tracing algorithms incorporating multiple reflection and diffraction [ $1-3]$. Although considerably better than their statistical counterparts, these models have been found to provide an unsatisfactory prediction accuracy in some situations [3]. In particular, it was shown in [3] that deterministic models treating the buildings as being opaque at UHF frequencies can seriously underestimate the field strength behind the first buildings surrounding the BS. Since the shielding of the BS antenna from its nearby environment is essential in the microcellular concept, it is of special interest to obtain a better understanding of the propagation phenomena responsible for this discrepancy.

In the framework of a collaboration between EUT, KPN Research and Swisscom, an extensive measurement campaign was carried out in several urban microcell environments in Switzerland. In this Letter, we present the results of a high-resolution angle-of-arrival (AOA) measurement conducted behind a large building obstructing the line-of-sight to the BS antenna.

Experimental arrangement: The measurements reported in this Letter were conducted using a wideband radio channel sounding system previously described in [4]. In summary, a 50Mchip/s pseudonoise (PN) sequence is used as the sounding signal which modulates a $2000 \mathrm{MHz}$ carrier, and estimation of the complex impulse response (CIR) of the radio channel is performed at the mobile receiver through correlation of the demodulated received signal with a replica PN sequence. The resulting time delay resolution is equal to the chip period $T_{c}$ of the applied PN sequence, which is 20 ns.

Transmission was from a $3 \mathrm{dBi}$ BS antenna (5m above ground level, which was well below the average roof top level of the surrounding buildings) to a mobile station (MS) equipped with a rotatable $2 \mathrm{dBi}$ omnidirectional antenna $(2.2 \mathrm{~m}$ above ground level). Impulse responses were measured along a horizontal circle with radius $r=30 \mathrm{~cm}$, thus effecting a synthetic uniform circular array (UCA) consisting of $M=106$ elements. 
For each propagation delay instant $\tau_{i}$ in the measured CIRs, the complex signals at the output of the $m$ th array element (with azimuth $\gamma_{m}$ ) can be expressed as

$$
y_{m}\left(\tau_{i}\right)=\sum_{n=1}^{N} s_{n}\left(\tau_{i}\right) e^{j \zeta_{n} \cos \left(\varphi_{n}-\gamma_{m}\right)}+\eta_{m}\left(\tau_{i}\right)
$$

where the summation is over the $N$ multipath signals contributing to the considered delay bin, $s_{n}$ and $\varphi_{n}$ are the complex amplitude and azimuth angle of the $n$th wave, $\zeta_{n}=2 \pi r \cos \left(\vartheta_{n}\right) / \lambda$ includes the elevation angle $\vartheta_{n}$ ( $\lambda$ is the wavelength), and $\eta_{m}$ is an additive noise signal. Based on the estimated covariance matrix of the vector $\left[y_{0}\left(\tau_{i}\right) y_{1}\left(\tau_{i}\right) \ldots y_{M}\left(\tau_{i}\right)\right]^{T}$ and an estimate of $N$, the UCA-MUSIC algorithm [4] provides high-resolution estimates of the AOAs, both in azimuth and elevation.

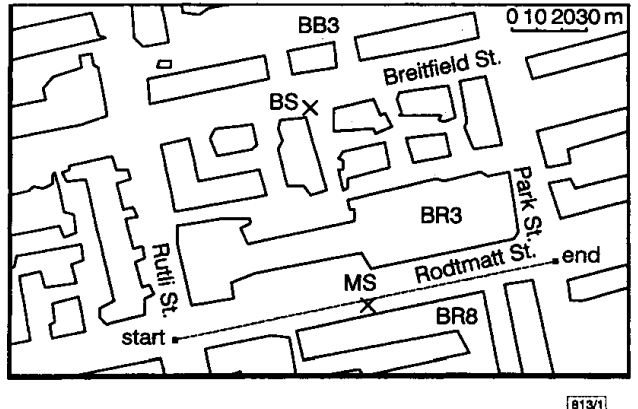

Fig. 1 Plan of urban microcell environment

Crosses indicate BS and MS locations

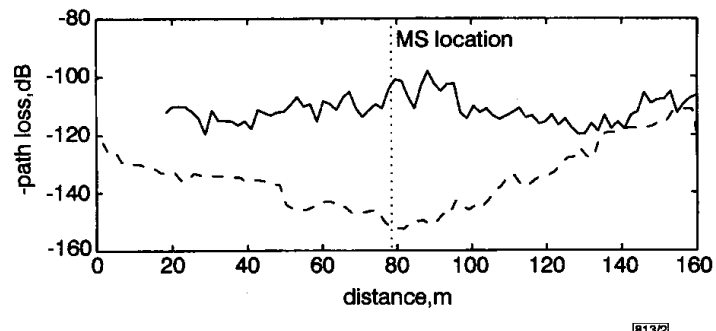

Fig. 2 Measured and predicted field strength along Rodtmatt Street measured predicted [3]

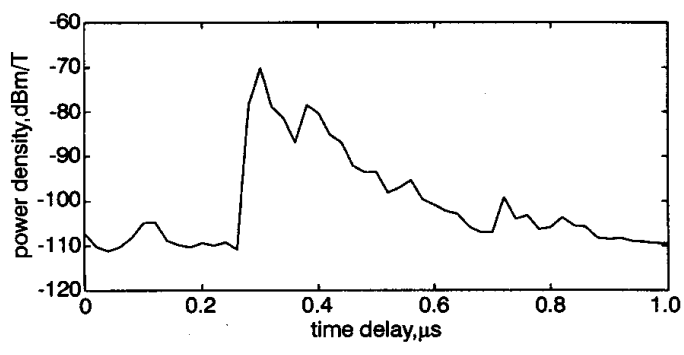

Fig. 3 Average measured power delay profile

8133

Results: The measurement results shown here were obtained in an urban microcell environment in Bern, Switzerland (Fig. 1), which is characterised by 3 to 4 storey concrete buildings, scattered vegetation and moderate traffic density. Fig. 2 shows the measured field strength along the trajectory shown in Fig. 1, together with the field strength predicted by the ray-tracing model described in [3], which takes into account all combinations of multiple specular reflection and single diffraction. It is seen that the field strength behind building BR3 is considerably and consistently underestimated by the prediction model.

The average power delay profile measured at the MS location indicated in Fig. 1, which is shown in Fig. 3, is dominated by two peaks, which were determined to be 28 and $35 \mathrm{~dB}$ below the freespace level. Fig. 4 shows the temporal and angular multipath distribution at the same location, and a panorama photograph taken from the receiver perspective. From this Figure it is clear that the propagation in the considered configuration is dominated by a series of strong contributions arriving from the direction of building 8R3. The corresponding values of $\zeta$ show that these waves are not the result of over-rooftop propagation (for which the elevation angle $\vartheta$ should be greater than $25^{\circ}$, or $\zeta<11.4$ ), but of transmission through BR3. The small angular spread of these multipath waves is probably the result of multiple scattering taking place inside the building. The weaker waves arriving from around $\varphi=200^{\circ}$ are reflected from building BR8, which is on the other side of the MS.

The second peak of the measured delay profile displayed in Fig. 3 appears as a second cluster of points in Fig. 4. The time delay difference between both clusters suggests that the second contribution is due to reflection from building BB3 (with reflection coefficient $-7 \mathrm{~dB}$ ) and subsequent transmission through BR3.

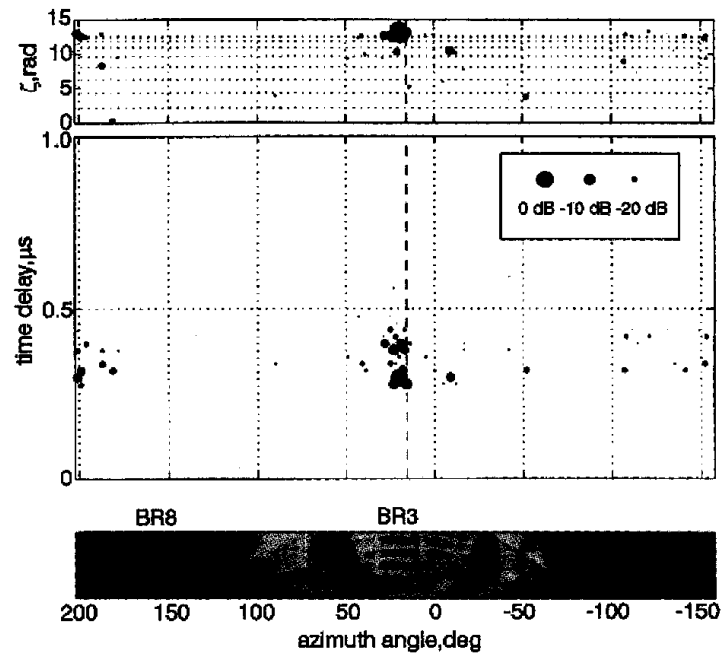

Fig. 4 Temporal and angular multipath distribution

Marker size indicates multipath wave amplitude relative to total power (down to $-30 \mathrm{~dB}$ ); elevation angles are represented through $\zeta=$ $2 \pi r \cos (\vartheta) / \lambda$; BS antenna position is indicated by dashed vertical line

Conclusions: The presented result shows that propagation through buildings surrounding the BS antenna can be the dominant propagation mechanism in urban microcells at UHF frequencies. This mechanism is commonly not taken into account by propagation prediction models used for the planning of microcells. The associated loss over freespace loss is $<30 \mathrm{~dB}$ in the situation considered in this Letter. Disregarding such a small shielding of the BS antenna in the planning stage of urban microcells may lead to unacceptable levels of inter-user interference.

Acknowledgments: The authors thank E. Zimmermann for his assistance with the measurements, and K. Rizk for making available the field strength prediction data.

(C) IEE 1999

Electronics Letters Online No: 19990467

8 March 1999 DOI: $10.1049 /$ el:19990467

Y.L.C. de Jong and M.H.A.J. Herben (Eindhoven University of Technology (EUT), Department of Electrical Engineering, PO Box 513 , $5600 \mathrm{MB}$ Eindhoven, The Netherlands)

J.-F. Wagen (Swisscom, Corporate Information and Technology, Ostermundigenstrasse 93, CH-3000 Bern 29, Switzerland)

A. Mawira (KPN Research, PO Box 421, 2260 AK Leidschendam, The Netherlands)

\section{References}

1 KANATAS, A.G., KOUNTOURIS, I.D., KOSTARAS, G.B., and CONSTANTINOU, P.: "A UTD propagation model in urban microcellular environments', IEEE Trans. , 1997, VT-46, (1), pp. 185-193 
2 RIZK, K., WAGEN, J.-F., and GARDIOL, F.: 'Two-dimensional ray tracing modeling for propagation prediction in microcellular environments', IEEE Trans., 1997, VT-46, (2), pp. 508-518

3 RIZK, K.: 'Propagation in microcellular and small cell urban environment'. PhD Thesis, Ecole Polytechnique Fédérale de Lausanne, Lausanne, Switzerland, 1997

4 DE JONG, Y.L.C., and HERBEN, M.H.A.J.: 'Accurate identification of scatterers for improved microcell propagation modelling'. Proc. 8th IEEE Int. Symp. Personal, Indoor and Mobile Radio Communications (PIMRC'97), Helsinki, Finland, Vol. 2, 1997, pp. 645-649

\section{Characterisation of rhenium Schottky contacts on $n$-type $\mathrm{Al}_{x} \mathrm{Ga}_{1-x} \mathrm{~N}$}

\section{Zhou, A.T. Ping, K. Boutros, J. Redwing and I. Adesida}

The electrical characteristics of Re Schottky contacts on $\mathrm{Al}_{x} \mathrm{Ga}_{1-x} \mathrm{~N}$ $(x=0,0.15,0.22$ and 0.26$)$ grown by MOCVD on sapphire substrates have been investigated. The effective barrier heights were obtained from current-voltage and capacitance-voltage measurements and were found to increase with aluminium concentration.

The study of Schottky barrier contacts on $\mathrm{Al}_{x} \mathrm{Ga}_{1-x} \mathrm{~N}$ is of great importance for the fabrication of high power and high temperature heterostructure field effect transistors (HFETs). To make gate contacts for such devices, metals are needed which form high barrier heights and are metallurgically stable. Significant work has been done in characterising the Schottky barrier heights of a variety of metals (i.e. $\mathrm{Ni}, \mathrm{Au}$ ) to $n$-type $\mathrm{GaN}$ [1]. However, the majority of these metals are not stable under high temperature operation. Refractory metals or metal silicides are more desirable for high temperature applications [2]. Rhenium has been predicted to form thermodynamically stable contacts on $\mathrm{GaN}$ [3]. Rhenium is more promising than tungsten because of its higher metal work function and its demonstrated ability to withstand annealing temperatures up to $700^{\circ} \mathrm{C}$ for $10 \mathrm{~min}$ without performance degradation [4]. To date, no Schottky characteristics have been reported for Re on AlGaN. Such a study is necessary for exploring the possibility of using rhenium as the gate contact metal in $\mathrm{Al}_{x} \mathrm{Ga}_{1-x} \mathrm{~N}$ HFETs. In this Letter, we report for the first time the Schottky characteristics of rhenium on $\mathrm{Al}_{x} \mathrm{Ga}_{1-x} \mathrm{~N}(x=0.15,0.22$ and 0.26$)$

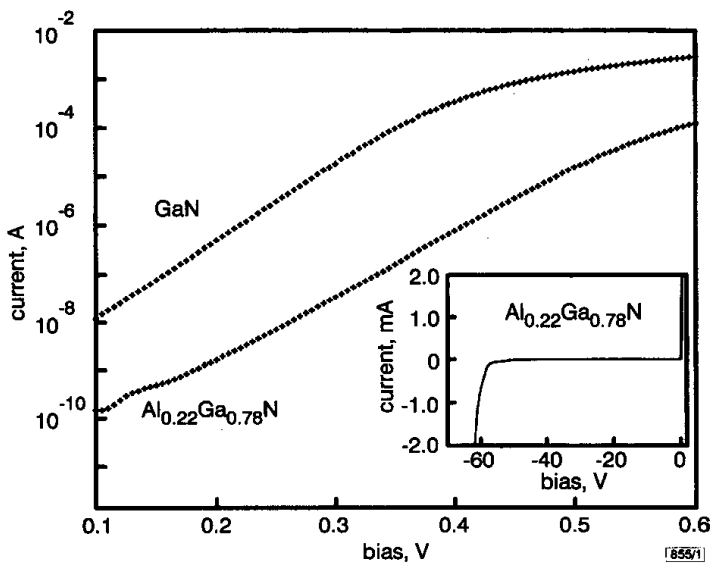

Fig. 1 Forward-bias $\log I-V$ characteristic for Re on $A l_{0.22} G a_{0.78} N$ and GaN

Inset: linear $\mathrm{I}-\mathrm{V}$ characteristic of Re contact on $\mathrm{Al}_{0.22} \mathrm{G}_{0.78} \mathrm{~N}$

The $\mathrm{Al}_{x} \mathrm{Ga}_{1-\mathrm{x}} \mathrm{N}$ layers used for this study were grown on $(0001)$ sapphire substrates by metal organic chemical vapour deposition (MOCVD) and consisted of $3 \mu \mathrm{m}$ thick undoped $\mathrm{Al}_{x} \mathrm{Ga}_{1-x} \mathrm{~N}$ followed by $1 \mu \mathrm{m}$ of Si-doped $\mathrm{Al}_{x} \mathrm{Ga}_{1-x} \mathrm{~N}$. The nominal bulk carrier concentration of the doped layers was $\sim 2.5 \times 10^{17} \mathrm{~cm}^{-3}$. The GaN layer used in this study had a similar structure with a nominal bulk carrier concentration of $1.4 \times 10^{17} \mathrm{~cm}^{-3}$. Photoluminescence was used to determine the aluminium concentration in the epilayers. The measured device structure consisted of an array of $250 \mu \mathrm{m}$ diameter Schottky dots separated $25 \mu \mathrm{m}$ radially from the Ohmic contact. Ohmic contacts were formed using a Ti/Al/Ti/Au multilayer that was rapid thermally annealed in an $\mathrm{N}_{2}$ ambient. Schottky contact dots were patterned using the metal lift-off technique. Prior to transferring the samples into the evaporation chamber, the surfaces were cleaned with an $\mathrm{O}_{2}$ plasma descum, followed by dips in dilute $\mathrm{HCl}: \mathrm{DI}$ and $\mathrm{HF}$ :DI solutions. E-beam evaporation was used to deposit Re to a thickness of $80 \mathrm{~nm}$. The Schottky diode characteristics were measured using current-voltage (I-V) and capacitance-voltage (C-V) techniques. The room temperature I-V and $\mathrm{C}-\mathrm{V}(1 \mathrm{MHz})$ measurements were carried out using an HP4142 and an HP4280 semiconductor analyser, respectively.

Fig. 1 shows the forward-bias log I-V characteristics of Re contacts on $\mathrm{Al}_{0.2} \mathrm{Ga}_{08} \mathrm{~N}$ and $\mathrm{GaN}$. The zero-bias barrier height $\phi_{b 0}$, and ideality $n$, were determined using eqn. 1 which assumes that thermionic emission is the predominant current transport mechanism [5]. Eqn. 1 is given by

$$
I=I_{0} \exp \left[q\left(V-I R_{s}\right) / n k T-1\right]
$$

with $I_{0}=S A^{* *} T_{2} \exp \left(-q \phi_{b 0} / k T\right)$, and where $R_{s}$ is the series resistance of the diode, $S$ is the contact area, and $A^{* *}$ is the effective Richardson constant. Theoretical $A^{* *}$ values of 26.4, 31.1, 33.2 and 35.8A $\mathrm{cm}^{-2} \mathrm{~K}^{-2}$ were used for $\mathrm{GaN}$ and $\mathrm{Al}_{x} \mathrm{Ga}_{1-x} \mathrm{~N}(x=0.15,0.22$ and 0.26 ), respectively. These values are based on linearly extrapolated effective electron masses using $m^{*}=0.22 m_{0}$ for GaN and $m^{*}=$ $0.48 m_{0}$ for AlN [6]. Since $\phi_{b 0}$ is voltage- and electric-field sensitive, a more appropriate barrier height to use is the flat-band barrier height $\phi_{b}$, given by [7]

$$
\phi_{b f}=n \phi_{b 0}-(n-1)(k T / q) \ln \left(N_{c} / N_{d}\right)
$$

where $N_{c}$ is the effective density of states for the conduction band and $N_{d}$ is the ionised dopant concentration.

The inset of Fig. 1 shows the linear I-V characteristics of the Re contacts on $\mathrm{Al}_{0.22} \mathrm{Ga}_{0.78} \mathrm{~N}$. The reverse-bias breakdown voltages for the $\mathrm{Re}$ diodes fabricated on $\mathrm{Al}_{x} \mathrm{Ga}_{1-x} \mathrm{~N}$ were clustered around $-55 \mathrm{~V}$. This number is consistent with the observed distribution of breakdown voltages for other Schottky metals on $\mathrm{GaN}$ analysed by Schmitz et al. [1]

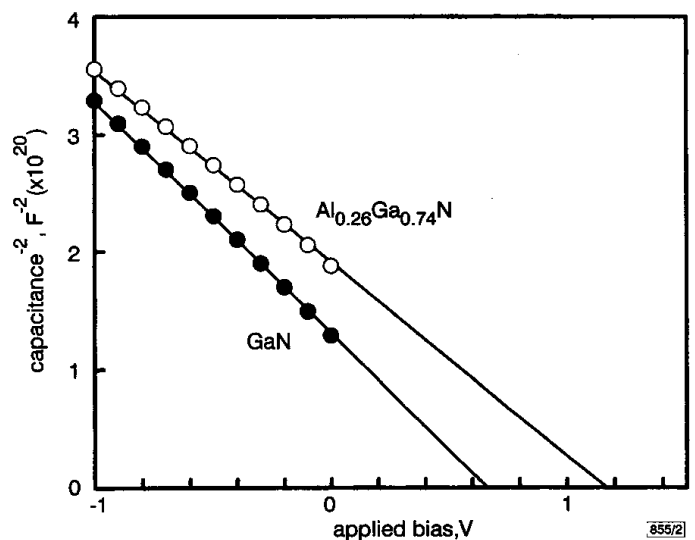

Fig. $21 / C^{2}$ against applied reverse bias for Re contacts on $A l_{0.26} G a_{0.74} N$ and $\mathrm{GaN}$

Fig. 2 shows a plot of $1 / C^{2}$ against the applied reverse bias for Re contacts on $\mathrm{Al}_{0.26} \mathrm{Ga}_{0.74} \mathrm{~N}$ and $\mathrm{GaN}$. The effective barrier height $\phi_{b}$ can be determined using the relationship given by [5]

$$
1 / C^{2}=2\left(\phi_{b}+V-k T / q\right) /\left(S^{2} q \varepsilon N_{d}\right)
$$

where $S$ is the contact area. Linearly extrapolated relative dielectric constants were used for $\mathrm{Al}_{x} \mathrm{Ga}_{1-x} \mathrm{~N}$ based on the values for GaN and AIN $\left(\varepsilon_{G a N}=0.95 \varepsilon_{0}, \varepsilon_{A I N}=0.90 \varepsilon_{0}\right)[6]$.

Table 1 summarises the Re Schottky characteristics from both the I-V and C-V measurements. Our measured barrier height for $\mathrm{Re}$ on $n$-GaN agrees very well with those obtained by Venugopalan 